\title{
Formalization, Communication Quality, and Opportunistic Behavior in R\&D Alliances between Competitors
}

\author{
SASCHA G. WALTER (corresponding author) \\ Lancaster University Management School \\ Lancaster, LA1 4YX, UK \\ Tel: +44 1524594847 \\ Email: s.walter@lancaster.ac.uk \\ ACHIM WALTER \\ Christian-Albrechts-University at Kiel \\ Institute for Innovation Research \\ Kiel, 24118, Germany \\ Tel: +494318803999 \\ Fax: +494318803213 \\ Email: walter@bwl.uni-kiel.de
}

DIRK MÜLLER

Business Development and Technology Transfer Corporation of Schleswig-Holstein Department for Start-up Development

Kiel, 24103, Germany

Tel: +4943166666849

Fax: +4943166666769

Email: mueller@wtsh.de

Journal of Product Innovation Management (forthcoming)

The final publication is available at Wiley via http://dx.doi.org/[DOI]

\begin{abstract}
For technology ventures (and also other firms), R\&D alliances provide great learning opportunities and access to scarce resources. However, R\&D alliances, in particular between competitors, also involve the concomitant threat of opportunistic behavior, which many firms attempt to manage by formalizing the partnership. Yet, prior research provided mixed findings suggesting that formalization alleviates opportunism, fails to do so, or, ironically, even promotes it. The questions of whether and, if so, when formalization can deter opportunism remains topical. This study differentiates two forms of opportunistic behavior, strategic manipulation and knowledge appropriation, and examines how they are affected by formalization, per se and in combination with communication quality. Findings from 82 R\&D alliances between competitors indicate that extensive formalization promotes opportunistic behavior. In contrast, communication quality mitigates the dysfunctional effect on strategic manipulation and also alleviates both forms of opportunism directly. Most effects vary with the type of opportunistic behavior.
\end{abstract}

Our findings add to the literature by demonstrating a positive formalization-opportunism relationship in the context of $\mathrm{R} \& \mathrm{D}$ alliances and by suggesting that relational governance (communication quality) compensates for the dysfunctional effects of formal governance 
(formalization), rather than both having complementary relationships. The results also support the call for more research into nuances of opportunism: they show that differentiating forms of opportunism matters for understanding the efficacy of safeguards against opportunism. Managers are warned against over-formalizing alliances, which spurs opportunism. Instead, they should cultivate an atmosphere of open communication, while they can still maintain some 'healthy distrust'. This attenuates the adverse effects of formalization, which is important since a certain level of formalization is often inevitable in $R \& D$ alliances.

Keywords: alliance, communication, opportunism, opportunistic behavior, R\&D, safeguards

JEL: D83, L24, L26, M13 


\section{INTRODUCTION}

Access to resources (van de Vrande et al., 2011) and access to technology-based and market-based learning (Afuah, 2000) are just two examples of what may motivate technology ventures to seek R\&D alliances with competing incumbents (Gnyawali et al., 2006). Yet such alliances saliently incur a risk of opportunistic behavior (Dickson et al., 2006; Hamel, 1991; Singh and Mitchell, 1996). In the worst case, the incumbent appropriates core technologies, putting the venture's long-term survival at stake (Alvarez and Barney, 2001). Inhibiting opportunism, therefore, becomes a key concern for any venture interested in conducting joint R\&D with a competing firm. One solution transaction cost economists (Williamson, 1985) and agency theorists (Eisenhardt, 1989; Jensen and Meckling, 1976) have proposed involves formalization, i.e. codifying desired outputs and/or behaviors and documenting these in the form of contracts, rules and procedures (cf. Vlaar et al., 2007a). ${ }^{1}$ However, prior research has yielded mixed findings showing that formalization effectively suppresses opportunism in interfirm exchanges (Judge and Dooley, 2006; Luo, 2007a), that it fails to do so (Deeds and Hill, 1999; Lui et al., 2009), or that formalization, ironically, promotes opportunism (Heide et al., 2007; Ju et al., 2011; Provan and Skinner, 1989). Thus, the questions of whether and, if so, when formalization can deter opportunism in $R \& D$ alliances remain topical.

In an attempt to address these questions, this study draws on prior work exploring opportunism in interfirm alliances. First, previous studies have demonstrated the destructive impact of partner opportunism — and even of the perception of opportunism—on alliance outcomes (Judge and Dooley, 2006; Lui et al., 2009; Luo, 2007b; Parkhe, 1993) and have tested deterrents against opportunism (e.g., Deeds and Hill, 1999). While these studies drew on broad measures of opportunism, Wathne and Heide (2000:37) have called to differentiate forms of opportunism: “[...] if nuances among forms of opportunism are unclear, deploying strategies for suppressing opportunistic behavior becomes problematic." More research along these lines is warranted, with a promising start made by recent studies (Das and Kumar, 2011; 
Jap et al., 2013; Lumineau and Quélin, 2012; Walter et al., 2010). Second, a small, but growing stream of literature has examined the formalization-opportunism link for general alliances (e.g., Judge and Dooley, 2006, Luo, 2007a). However, contradictory findings indicate that this relationship is, to date, not well-understood, in particular for the specific case of R\&D alliances (Deeds and Hill, 1999; Vanhaverbeke et al., 2012). Finally, there is a longstanding debate in the alliance literature on whether formal and relational governance complement (e.g., Poppo and Zenger, 2002) or substitute (e.g., Dyer and Singh, 1998) one another in shaping alliance performance. Relatively little is known on their interactive or substitutive effect on partner opportunism.

This study helps filling above gaps by developing a more nuanced understanding of opportunism and by exploring the role of formalization, per se and in interaction with relational governance in terms of communication quality. The article starts with differentiating two forms of opportunistic behavior salient in R\&D alliances: strategic manipulation, i.e. one partner influences their counterpart's strategic orientation to pursue individual gains at the counterpart's expense, and knowledge appropriation, i.e. internalizing a partner's knowledge without their agreements in ways that are counter to the firm's strategic interests (Doz, 1987; Katila et al., 2008). The article then builds on the literature on coordination, cooperation, and sensemaking (e.g. Gulati et al., 2005; Gulati et al., 2012; Vlaar et al., 2006) to argue that high levels of formalization increase opportunistic behavior perceived by technology ventures (our focal firms). Moreover, communication quality - the extent to which the partners exchange meaningful and timely information in an open and honest manner (cf. Anderson and Narus, 1990; Sivadas and Dwyer, 2000)—is introduced as an important influence that mitigates perceived opportunistic behavior and the dysfunctions of formalization. Finally, it is suggested that the direct and interactive effects of formalization and communication quality differ depending on the type of opportunistic behavior. 
The study adopts the perspective of a focal firm, a technology venture in a dyadic exchange with a competing incumbent, where the venture reports on its own position, on the circumstances of the partnership, and on the counterpart's behavior. In this under-researched but important context (Afuah, 2000; Gnyawali et al., 2006; Katila et al., 2008), the tension between cooperation and competition resides not only in the alliance, but also in the market (Gnyawali et al., 2006). Risks of opportunism and the vulnerability of technology ventures tend to be high in such alliances (Alvarez and Barney, 2001). Data from 82 R\&D alliances between technology ventures and established competitors supports many of our arguments. Overall, our study extends the literature on multiple fronts. First, it demonstrates dysfunctional effects of formalization in the context of R\&D alliances. Second, it introduces communication quality as an important relational influence that directly suppresses opportunism and compensates for the dysfunctions of formalization. Third, it provides a nuanced view on opportunism and demonstrates that both the dysfunctional effect of formalization as well as the interactive effect of communication quality vary with the type of opportunism studied.

\section{THEORETICAL DEVELOPMENT}

\section{Opportunism in R\&D alliances}

Since Williamson's (1975:6) original, broad definition of opportunism as “self-interest seeking with guile", theorizing about opportunism has increasingly become more nuanced. ${ }^{2}$ Williamson himself (1985:47) made a start by specifying the term "guile" as "calculated efforts to mislead, distort, disguise, obfuscate, or otherwise confuse". He also distinguished between ex-ante opportunism, including various forms of deliberate misrepresentation during alliance initiation, and ex-post opportunism, including various forms of violations over the course of the alliance. Other scholars have suggested that opportunism in strategic alliances can manifest itself in such activities as appropriating knowledge, evading obligations, 
breaching contracts, overstating capabilities, or holding up the partner (Dickson et al., 2006; Hamel, 1991; Luo, 2007a). Similarly, Das (2005:707) has pointed to the variety of opportunistic behavior, including for instance "withholding or distorting information and shirking or failing to fulfill promises or obligations". Despite attempts to theoretically differentiate specific forms of opportunistic behavior, empirical studies on alliances have predominantly focused on general forms of opportunism (e.g., Judge and Dooley, 2006; Luo, 2007b; Parkhe, 1993; Provan and Skinner, 1989). More research into nuances of opportunistic behavior is important to better understand the opportunism phenomenon and the efficacy of various suppression strategies (Wathne and Heide, 2000).

Das and Kumar (2011) and Lumineau and Quélin (2012) made a promising start by illuminating the manner in which alliance partners behave opportunistically. They drew on Wathne and Heide's (2000) categorization of active and passive opportunism, having its theoretical roots in transaction cost economics and relational contracting theory. Passive opportunism occurs when a partner refrains from particular actions. Examples include shirking, evasion of obligations, inflexibility or refusal to adapt to new circumstances. Active opportunism occurs when a partner engages in particular actions, such as engaging in explicitly or implicitly prohibited behaviors or using changed circumstances to extract concessions from the other partner. Since this type of opportunism may often be salient, we focus on the active category. In particular, two facets of active opportunism are suggested based on the extant literature. The first is strategic manipulation, this is according to our definition one partner influencing their counterpart's strategic orientation in order to advance their own interest at their counterpart's expense. The risk that partner pursue own, strategic interests is particularly high in alliances between (potential) rivals (Baum et al., 2000). To give an example: in 2000 Net2Phone and Cisco formed an R\&D alliance to make their products more compatible and marketable. Later, Net2Phone accused its former partner of having rushed the firm into acquiring another competitor, and thereby of inhibiting the firm's 
further development in order to advance its own competing products. To illustrate the severity of the consequences, experts have estimated that Net2Phone could have sought as much as $\$ 700$ million in total damages, even as its market capitalization was \$316 million (Wall Street Journal, 2002). Similarly, findings of Sarkar et al. (2001) suggest that firms sometimes hamper alliance partners' achievement of strategic learning objectives purposefully.

The second type of opportunistic behavior is knowledge appropriation which occurs when a firm internalizes a partner's knowledge without their agreements in ways that are counter to the latter's strategic interests (Doz, 1987; Katila et al., 2008). The literature on knowledge-based alliances suggests unintended knowledge transfer as a key concern among partners (e.g., Katila et al., 2008; Li et al., 2008; Oxley and Sampson, 2004; Sampson, 2007). Appropriating a partner's knowledge can be viewed as one form of opportunistic behavior (Emden et al., 2006) that is a serious threat for small entrants engaging in R\&D alliances with larger incumbents (Alvarez and Barney, 2001; Baum et al., 2000). R\&D collaborations are typically susceptible to open, unrestricted knowledge sharing often observed by engineers at the operative level. Seemingly insignificant technical details such as the size of a socket in a laboratory can reveal critical information about one partner's ongoing research projects to the other. One example of knowledge appropriation is the R\&D collaboration between Sendo and Microsoft to develop the first phone using a mobile version of the Windows operating system. Sendo later sued their partner for having stolen key technology and passing it to HTC to produce a Windows-based phone at low costs (Business Week, 2003). A second example is the development of the Apple Macintosh in the 1980s (Li et al., 2008). While developing applications for Apple, Microsoft gained access to critical knowledge about Apple's Graphical User Interface. This enabled Microsoft to create Windows and to enter the market for operating systems.

The literature proposes several mechanisms for discouraging opportunism among partners. While mechanisms for all stages of an alliance are available (Das and Rahman, 
2002), establishing safeguarding mechanisms especially in the formative stage may be critical for vulnerable, resource-starved technology ventures such as our focal firms. Such mechanisms may for instance include selecting partners with low opportunistic propensity (Wathne and Heide, 2000), making mutual, idiosyncratic investments (Heide and John, 1988) and aligning partner goals (Jap and Anderson, 2003). One measure that has received special attention in the literature, however (and one that has produced paradoxical empirical findings) is formalization (e.g., Crosno and Dahlstrom, 2008; Hawkins et al., 2008; Vlaar et al., 2006). Scholars have discussed various, partly intertwined functions of formalization in interfirm relationships: it helps guide and monitor partner behavior (control function; e.g. Carson et al., 2006; Williamson, 1985) and align partner activities (coordination function; e.g. Gulati et al., 2005; Malhotra and Lumineau, 2011), and it fosters mutual understanding among partners (sensemaking function; e.g., Vlaar et al., 2006). Against this backdrop, the subsections below argue why formalization should increase perceived opportunistic behavior in terms of strategic manipulation and knowledge appropriation and why communication quality should mitigate this effect.

\section{Formalization and perceived opportunistic behavior}

Some formalization may be required in R\&D alliances — in particular between competitors (Alvarez and Barney, 2001; Larson, 1992) — and is widely regarded as beneficial (Judge and Dooley, 2006; Luo, 2007a; Oxley, 1997). However, a small, but growing stream in the alliance literature has questioned the safeguarding efficacy of formalization (e.g., Provan and Skinner, 1989; Vlaar et al., 2007a) because extensive formalization consumes considerable resources and results in agreements that are often (and inevitably) incomplete and not fully enforceable (Dickson et al., 2006; Williamson, 1985). Against this backdrop, we now argue that high levels of formalization are positively rather than negatively related with perceived opportunistic behavior. A straightforward argument is that superior monitoring 
does not produce more opportunistic behavior per se, but simply increases the partners' chances of detecting such behavior. In other words, formalization may increase a firm's sensitivity to partner opportunism (real or suspected) without affecting its frequency. However, there are arguments beyond this simple notion.

First, extensive formalization can induce a failure of its control function by impairing partner motivation to collaborate. Jap and Ganesan (2000), for instance, found explicit contracts to have a negative impact on partner commitment. Also findings by Falk and Kosfeld (2006) suggest that a principal's controlling decision reduces the agent's performance, who perceives this as a limitation of choice autonomy and signal of distrust. Formalization can thus hamper one or both partners' intrinsic motivation and commitment to an alliance and thereby lead them to pursue selfish rather than common goals. Moreover, according to Heide, Wathne, and Rokkan (2007), enhanced monitoring of partner behavior, one of the key benefits of formalization, can, ironically, result in 'reactance types of effects': it can lead to attitudes and behaviors that the counterpart can easily interpret as being defensive in nature and as such indicative of opportunism. For instance, if a technology venture insists on detailed work plans with tight deadlines, engineers of the incumbent can perceive this as an obtrusive form of control, leading them to ignore the request. This, in turn, can lead the venture to suspect opportunism. Indeed, studies have demonstrated a positive link between surveillance and opportunistic behavior (Crosno and Dahlstrom, 2008; Hawkins et al., 2008; Provan and Skinner, 1989). Similarly, Schweitzer et al. (2004) have found that goal setting, one important aspect of formalization, has the unintended consequence of motivating unethical behavior, such as overstatement or false claiming of accomplishments, when partners fall short of reaching their goals.

Second, a partner is more likely to misinterpret the counterpart's behavior in highly formalized alliances - a failure of the sensemaking function of formalization. Since formalization can reflect the way a firm views partner behavior, firms demanding more 
extensive formalization are likely to be more suspicious and to regard a particular action on the part of their partner as opportunistic, whereas more optimistic firms would not be so suspicious (Das and Rahman, 2002). Formalization not only increases perceptions of social distance and signals distrust (Ghoshal and Moran, 1996), but it can also create mechanistic management practices allowing little room for adaptation (Blatt, 2009). If circumstances change, a firm pressing for a modification may interpret a partner's insistence on the original arrangement as counterproductive or selfish behavior (Wathne and Heide, 2000). Thus,

Hypothesis 1: The higher the formalization, the higher the opportunistic behavior (in terms of strategic manipulation and knowledge appropriation) perceived by the technology venture.

\section{Communication quality and perceived opportunistic behavior}

Relational governance has long been suggested as an alternative to formalization that overcomes the inevitable incompleteness of formal arrangements (Macneil, 1980; Dyer and Singh, 1998). It provides a flexible and cost-efficient mechanism as alliances evolve over time (Doz, 1996) and environmental changes occur (Luo, 2007b). ${ }^{3}$ It also promotes the development of trust among the alliance partners (Gulati, 1998). Prior research on relational governance has revolved around the concepts of trust (e.g., Das and Teng, 1996, 1998, 2001, Lui and Ngo, 2004) and of more general relational norms (e.g., Poppo and Zenger, 2002). However, alliance scholars increasingly consider communication an important means to achieve cooperation and coordination in alliances (Agarwal et al., 2010; Mohr and Spekman, 1994; Zeng and Chen, 2003). A climate of open communication emerges in some, but not all alliances (Doz, 1996). We now suggest that communication quality is negatively related to perceived opportunistic behavior. 
Collaborative research requires the partners to continuously provide one another with detailed information. Open communication promotes a continuous flow of information between the parties (Kogut, 2000; Larson, 1992) and also enables legitimate interfirm learning and goal adjustment (Sivadas and Dwyer, 2000). Communication evokes partner support (Mohr and Spekman, 1994) and signals commitment to and interest in a lasting collaboration (Gundlach et al., 1995). Communication reduces coordination costs and promotes cooperation through moral suasion, development of group identity, and trust (Agarwal et al., 2010; Zeng and Chen, 2003). Consequently, communication quality increases an alliance's potential value, which motivates the partners to seek long-term, mutual benefits rather than immediate, unilateral benefits through opportunistic behavior.

Moreover, since communication quality requires mutual investments by the partners and takes time to develop, it can serve as additional safeguard. If unforeseen events render the initial structural design obsolete, communication quality can deter partner misconduct and stabilize the partnership. Formalization cannot possibly stipulate every potential contingency, as managers are constrained in their ability to anticipate the future (Macneil, 1980). Unexpected disturbances can impair the efficacy of existing structural safeguards (Ariño et al., 2008) and destabilize an ongoing partnership (Williamson, 1975). In this situation, open communication sustains inter-partner trust (Gulati, 1998), reassures both partners that each will act in good faith (Das and Teng, 2001) and will not opportunistically exploit the absence of other safeguards. In this way, communication can prevent a dangerous sequence of opportunistic action and reaction between partners. Thus,

Hypothesis 2: The higher the communication quality, the lower the opportunistic behavior (in terms of strategic manipulation and knowledge appropriation) perceived by the technology venture. 


\section{The interplay of formalization and communication quality}

The academic debate on whether formal and relational governance complement (e.g., Faems et al., 2008; Li et al., 2010; Lui and Ngo, 2004; Mellewigt et al., 2007; Poppo and Zenger, 2002; Ryall and Sampson, 2009), substitute for (e.g., Carson et al., 2006; Dyer and Singh, 1998; Granovetter, 1985), or impair one another (e.g., Ghoshal and Moran, 1996) has not waned. Our study adds to this line of work by suggesting that, regardless of whether it emerged prior to or during an ongoing partnership, communication quality alleviates the effect of extensive formalization on opportunistic behavior for two reasons. First, communication quality compensates for the demotivating effects of formalization. It has been long suggested that relational concerns can mitigate the tendency to act opportunistically (Coase, 1988: 44). Communication reinforces relational concerns by evoking partner support (Mohr and Spekman, 1994) and by signaling commitment to a long-term cooperation (Gundlach et al., 1995). Similarly, Jap et al. (2013) have proposed that in a relationship characterized by sympathy, accord, and cooperation ("rapport") the moral costs of misbehavior increase and thereby inhibit opportunism. Also Heide et al. (2007) found that relational elements, in terms of micro-level social contracts, buffer the dysfunctional effects of behavior monitoring. Second, communication quality mitigates the risk of serious misunderstandings that may arise from the use of formalization. In general, the difficulty of correctly interpreting partner behavior can lead to suspicion, and suspicion to distrust (Agarwal et al., 2010). The request by one partner to establish extensive structural safeguards can easily be misconstrued by the other as a sign of distrust. Another misunderstanding can occur if one firm, failing to meet a requirement defined in interfirm agreements, is suspected by the other side, by reason of this failure, of having acted opportunistically. If communication quality is too low to clarify the situation, retaliatory behavior is a likely consequence (Gundlach et al., 1995), and the partnership might degenerate into a vicious cycle of opportunistic actions by both partners. By contrast, if communication quality is high, 
the partners may clarify the situation and re-establish a climate of cooperative behavior (Zeng and Chen, 2003). Communication reduces the risk of a 'pre-emptive strike' based on misunderstanding by promoting mutual understanding between the partners (Stephen and Coote, 2007). Thus,

Hypothesis 3: Communication quality decreases the positive relationship between formalization and opportunistic behavior (in terms of strategic manipulation and knowledge appropriation) perceived by the technology venture.

\section{Differences between strategic manipulation and knowledge appropriation}

The preceding sections did not differentiate forms of opportunistic behavior. We now argue why the effect strengths of formalization and communication quality, per se and in interaction, should differ for strategic manipulation and knowledge appropriation. The differential effects may be caused by two mechanisms. First, since both types of opportunistic behavior vary in terms of intentionality, severity and mutuality, they vary in the likelihood to be tolerated by a victim and in their potential costs. Strategic manipulation is intentional and connotes overtly unethical behavior. It is often long-planned and tends to have drastic consequences for the victim, as exemplified by the Net2Phone-Cisco case (Wall Street Journal, 2002). The offender clearly focuses on maximizing individual benefits at partner costs. Since a direct remedy for such a severe misconduct seems difficult, strategic manipulation is likely to be a 'deal-breaker' that, if detected, results in an early termination of the alliance. Thus, it seems plausible to assume that strategic manipulation typically represents high-stakes opportunism (Jap et al., 2013). In contrast, knowledge appropriation can take the form of intentional and overt attempts to outlearn the partner (Hamel, 1991), but can also be understood as originating in unintentional spillovers of knowledge that occur without managerial intention at operational levels, when for instance engineers of both 
partners exchange information freely. $R \& D$ alliances are conducive to such spillovers because finding the right balance of knowledge sharing and protection is difficult (Oxley and Sampson, 2004). A victim of knowledge appropriation may often be compensated by own learning, either through bilateral spillovers or own attempts to internalize partner knowledge (Hamel, 1991). While the consequences of knowledge appropriation for the alliance may depend on perceptions of its intentionality and severity, we assume knowledge appropriation, given that it may often be unintentional and/or mutual, predominantly represents low-stakes opportunism (Jap et al., 2013). Second, partnerships characterized by harmony and mutual understanding are conducive to mild forms of opportunism but not strong forms. In such partnerships, the opportunistic party tends to engage in morally malleable reasoning to justify mild opportunistic behavior (Jap et al., 2013).

Beyond this backdrop, we now suggest that the positive link between formalization and opportunistic behavior (Hypothesis 1) is stronger for knowledge appropriation than for strategic manipulation. As argued above, formalization can reduce commitment or evoke reactance, leading the partners to take actions to improve their condition (Provan and Skinner, 1989). This stimulus to opportunistic behavior tends to result in knowledge appropriation rather than strategic manipulation because formalization propels interfirm learning (Vlaar et al., 2007a) and facilitates the acquisition of difficult to protect tacit knowledge (Liebeskind, 1996), for instance by defining interfaces for knowledge exchange (Puranam and Jacobides, 2006) and by connecting key knowledge holders across firm boundaries. Moreover, while formalization can increase the perception of suspicious behavior in general (Vlaar et al., 2007a), a partner is more likely to suspect (or misperceive) knowledge appropriation than strategic manipulation. This is because interfirm learning, legitimate or illegitimate, is often mutual (Hamel, 1991) and mutuality makes opportunism more easily justified (Jap et al., 2013) and therefore more likely. In contrast, strategic manipulation is less likely because its 
detection may disrupt the alliance and entails substantial reputational costs for the opportunistic partner. Thus,

Hypothesis 4a: The positive effect of formalization is stronger for knowledge appropriation than for strategic manipulation.

Hypothesis 2 postulated that communication quality deters opportunistic behavior. We now argue that this effect is stronger for strategic manipulation than for knowledge appropriation. Communication quality mitigates opportunism by creating a supportive and trust-based climate in the alliance which raises the pay-off from collaborative vis-à-vis selfish behavior. While many alliance partners may take precautions to maintain the good relationship, open communication also promotes intentional or unintentional knowledge flows, thereby creating a higher potential for knowledge appropriation. A climate of open communication can mislead in particular employees at the operative level to share proprietary information and justify the sharing on grounds of mutuality and familiarity. For instance, Czepiel (1974) found that informal communication drives the diffusion of innovation among firms. Moreover, communication quality requires reciprocal investments by the partners and thus serves as a safeguard against opportunism. A victim is likely to consider the value of their investments when deciding about an appropriate response to opportunistic behavior. Such a cost-benefit rationale may lead many partners to tolerate mild forms of opportunism (Wathne and Heide, 2000). In contrast to strategic manipulation, knowledge appropriation is easier to justify as being unintentional, less severe and/or mutual, making it more likely to be tolerated. Some partners may anticipate the tolerance limit and engage in knowledge appropriation, regardless of communication quality. Thus, 
Hypothesis 4b: The negative effect of communication quality is stronger for strategic manipulation than for knowledge appropriation.

Finally, we suggest that communication quality is more likely to remedy the dysfunctional effect of formalization on strategic manipulation than on knowledge appropriation (cf. Hypothesis 3). Open communication can shape relationships characterized by interpersonal harmony and mutual understanding (Zeng and Chen, 2003). Jap et al. (2013: 218) label such relationships "rapport" and suggest that they are conducive to morally malleable reasoning where alliance partners justify opportunistic behavior by arguing, for instance, that "an opportunistic act is not so bad, that the person taken advantage of would not mind, or that the transaction partner likely already knows and implicitly approves of this activity". In high rapport settings, the partners tend to view mild forms of opportunism ("lowstakes opportunism") as being victimless and normal, whereas high-stakes opportunism would be difficult to justify. Indeed, Jap et al. (2013) observed stronger opportunistic tendencies, when the stakes were low and rapport high, and explained this by an increase in malleable reasoning. Communication quality is a concept related to rapport. Knowledge appropriation can be regarded as a form of low-stakes opportunism and strategic manipulation as high-stakes opportunism. It is therefore suggested that knowledge appropriation as opposed to strategic manipulation is more likely in alliances high in communication quality. While communication quality may still mitigate dysfunctions of formalization, the above mechanism creates a countervailing effect for knowledge appropriation. The mitigating effect formulated in Hypothesis 3 is thus expected to be stronger for strategic manipulation. Thus,

Hypothesis 4c: The moderating effect of communication quality is stronger for strategic manipulation than for knowledge appropriation. 


\section{METHODS}

\section{$R \& D$ coopetitions as research context}

Alliances between direct or potential competitors are characterized by a permanent tension between cooperation and competition, residing not only within the alliance but, unlike with other types of alliance, also in the market (Gnyawali et al., 2006). This can increase partners' motivation to maximize their own immediate, tangible benefits by behaving opportunistically rather than to maximize their potential (but uncertain) long-term, collective benefits by acting collaboratively (Bengtsson and Kock, 2000; Park and Ungson, 2001). For instance, if critical market information, such as prices for key accounts, is accidently revealed throughout a partnership, a direct rival can woo away customers to increase its own market share to the detriment of the partner. Also, if the collaboration facilitates one partner's overcoming the knowledge barriers to market entry, that partner can go from being an indirect or potential rival to being a direct rival. Risks of knowledge appropriation are salient in R\&D alliances (Larson, 1992; Park and Kim, 1997) and are even higher if competitors are involved: per definition, the partners typically meet similar market needs and/or have the required capabilities to do so (Peteraf and Bergen, 2003). Since they operate in similar fields and possess related market and/or technology knowledge, inter-partner learning tends to be higher than in other types of alliance (Cohen and Levinthal, 1990; Dussauge et al., 2000). ${ }^{4}$ Given the high risks, alliances between competitors provide a conducive setting for the purpose of our study. Moreover, this study focuses on technology ventures as focal firms for two reasons. First, such firms intensively engage in R\&D and often seek alliances to overcome resource constraints (Katila et al., 2008). Second, because they are particularly vulnerable to knowledge appropriation and strategic manipulation, effective safeguarding becomes a key concern (Alvarez and Barney, 2001). 


\section{Sample and procedure}

Our study is part of a larger survey on alliances of technology ventures with (potentially) competing incumbents (cf. Walter et al., 2010). Our sampling frame included technology ventures that run a business model based on a technological invention, collaborate with a potential, indirect, or direct competitor (Peteraf and Bergen, 2003), and are organizationally independent, headquartered in Germany and not older than ten years. In any given dyad, only the venture was surveyed because confidentiality agreements typically precluded their revealing the counterpart's identity. Having no comprehensive list, we compiled our own initial list of about 2,750 firms from print media and the internet. In particular, we used keyword searches and browsed the websites of industry fairs, support programs, industry associations, science parks and research organizations. We called a onethird quota of 883 randomly selected firms, of which 207 firms met our sampling criteria and agreed to participate. Trained interviewers then conducted face-to-face interviews with one informant at the upper management level, in particular a manager or founder who negotiated and structured the alliance. The interviewee was asked to report on the strategically most important alliance, irrespective of its success, that involved a potential, direct or indirect competitor and was old enough to evaluate its outcomes. Prior to the main interview, the interviewer double-checked that the alliance met the requirements of our survey.

To mitigate the problem of a common method bias, we attempted to survey another informant at the operative level, in particular a project or alliance manager. The operative informant reported on strategic manipulation, knowledge appropriation and communication quality in an alliance named by the first informant. The managerial informant reported on the remaining constructs and variables. 118 of 207 firms participated in the second survey. Of these, 82 had alliances with an R\&D focus and constitute our final sample. ${ }^{5}$ To test for nonresponse bias, we compared respondents and non-respondents in terms of age, size, and technological field. No significant differences emerged, indicating little danger of non- 
response bias. The technology ventures were on average 3.46 years old $(\mathrm{sd}=2.93)$, employed 23.39 full-time equivalents ( $\mathrm{sd}=27.79$ ), and were operating in the fields of biotechnology (25\%), electronics (20\%), nanotechnology/new materials (20\%), software/simulation (11\%), and others $(25 \%)$. The partner firms were on average 24.49 years old $(\mathrm{sd}=36.38)$ and larger in terms of sales $($ mean $=5.42, \mathrm{sd}=1.92)$ and employees $($ mean $=5.38, \mathrm{sd}=1.78)$, as reported by the respondents on 7-point Likert-scales $(1=$ "much smaller [than the focal firm]", 7 = "much larger").

\section{Measures}

\section{Dependent variables}

The extant literature provides measures for general opportunistic behavior (e.g., Provan and Skinner, 1989; Luo, 2007b), but not for its more specific manifestation in strategic manipulation or knowledge appropriation. We therefore developed scales using a procedure proposed by Rossiter (2002). In particular, after an initial construct definition we involved expert raters to clarify whether a formative or reflective measurement model is more appropriate for a given construct and, if formative, whether the domain was captured completely. This procedure helps avoid the kind of misspecification that has plagued past studies (Jarvis et al., 2003). All scales were pre-tested in three successive rounds with two or three CEOs of technology ventures and revised up to the point where all pre-testers confirmed that the items were clear, meaningful, and relevant. An overview of all scales and validity information is presented in the Appendix.

Prior research has captured perceived opportunistic behavior in terms of both process and outcomes (e.g., Deeds and Hill, 1999; Luo, 2007b; Parkhe, 1993). Process measures indicate whether a focal firm has 'caught a partner red-handed' engaging in seemingly opportunistic activities, whereas outcome measures describe the results of such activities as observed by the focal firm ex-post. ${ }^{6}$ For two reasons, we have focused on the latter to 
operationalize strategic manipulation and knowledge appropriation. First, initial observations of opportunistic activities can lead to further investigations possibly revealing more opportunistic activities. This suggests that the scope of opportunistic behavior may be more adequately evaluated from an ex-post perspective. Second, a firm's response to opportunism may greatly depend on the impact of that opportunism (e.g., an erosion of the firm's knowledge base) rather than on isolated observations of partner misconduct (e.g. of lying or obfuscating).

We used conceptual writings about alliance risks, alliance contracts, and exchange problems (Alvarez and Barney, 2001; Barney and Hesterly, 2006) as basis for creating multiitem scales of opportunistic behaviors. Strategic manipulation was measured with three reflective items capturing the degree to which a partner purposefully exerts a negative influence on the strategic decisions of the technology venture. The items were-like all the items in the following, unless stated otherwise - measured on a 7-point Likert-scale $(1=$ "does not apply at all"; 7 = "applies fully and completely"). The measure is reliable at an alpha of 0.86. Knowledge appropriation was measured as the sum of four formative items similar to Norman (2004). The respondents stated to what extent they had 'lost' critical codified or tacit knowledge in the areas of marketing, technology, production, and management to the partner firm. ${ }^{7}$ To test the validity of our formative measure (an area of ongoing debate), we examined (1) content validity by asking expert judges, (2) nomological or criterion validity by investigating the correlation between the measure and a theoretically linked measure, and (3) discriminant validity by testing whether the constructs are less than perfectly correlated (MacKenzie et al., 2005; Rossiter, 2002). ${ }^{8}$ Both content and discriminant validity were confirmed. Knowledge appropriation were, as theoretically expected, positively related to a measure for closure by the partner firm $(r=.35, p<.01$; Hamel, 1991), which indicates criterion validity. 


\section{Independent and control variables}

To capture formalization, the respondents stated the degree to which written documents existed that spelled out detailed processes, roles, responsibilities, and tasks within the alliance. The four items are conceptually based on Lusch and Brown (1996) and are reliable at an alpha of 0.95. Communication quality was measured with five reflective items adapted from the extant literature (Anderson and Narus, 1990; Sin et al., 2005; Sivadas and Dwyer, 2000). The scale is reliable at an alpha of 0.89 .

To isolate the effect of our predictor variables, we considered several critical control variables. Equity exchanges deal with whether at least one partner holds equity in the counterpart $(1=$ equity exchanges, $0=$ otherwise $)$. Opportunistic behavior is detrimental to the value of this investment and therefore discouraged (Gulati, 1995; Judge and Dooley, 2006). Cooperation experience was operationalized as the number of years a manager (Informant 1) had worked with alliances. Such experience can help to effectively structure and coordinate such partnerships and thereby avoid the risks (and reap the benefits) of alliances (Sampson, 2005). Cooperation duration measures the number of months from the operative start until the end of the collaboration, as stated by the respondents. The risk of opportunism is believed to vary over time (Das, 2004).

Incumbents with both the motivation and the ability to force the technology venture out of the market might behave more opportunistically. We therefore controlled for risk of opportunism, conceived of as the product of one item for the motivation ("It would have been very worthwhile for the partner to squeeze us out of the cooperation-related markets.”) and another item for the ability ("The partner had the potential to squeeze us out of the cooperation-related market.”). Learning intent deals with the possibility of a focal firm attempting to appropriate partner knowledge and thereby potentially initiating a learning race (Hamel, 1991). It was measured with three reflective items $(\alpha=.75)$. Finally, relational governance is often associated with trust (Jassawalla and Sashittal, 1998; Nooteboom, 1996; 
Sherwood and Covin, 2008). While prior research has distinguished goodwill and competence trust (e.g., Das and Teng, 2001), limited questionnaire space led us to use a three-item overall measure $(\alpha=.88)$. Goal congruence creates win-win situations between the parties and thereby discourages opportunistic behavior. Our three-item measure was adapted from Jap and Anderson (2003, $\alpha=.62)$.

\section{Endogeneity analysis}

Endogeneity bias has the potential to distort our results if governance not only affects opportunistic behavior but concerns about opportunistic behavior also affect governance. In other words, a technology venture could deploy more extensive safeguards in seemingly riskier alliances. Simultaneous causality might also exist in the relationship between communication quality and opportunistic behavior. In the case of endogeneity, independent variables and the error term are correlated. This violates the exogeneity assumption of ordinary least square (OLS) estimation and produces biased, inconsistent coefficients. According to Wooldridge (2003), two-stage instrumental variables regression can mitigate endogeneity bias, but it inflates standard errors and thus tends to be less efficient than OLS. It is therefore prudent not to empirically model a variable as endogenous until tests suggest that endogeneity is a statistical problem. We therefore conducted a Durbin-Wu-Hausman test on endogeneity (Wooldridge, 2003:121-122). In this test, all endogenous variables are first regressed on the other independent variables plus instruments, and then opportunistic behavior is regressed on the independent variables plus the fitted residuals from the first regressions. Statistical significance of the residuals indicates endogeneity bias.

We started with selecting two instruments variables for formalization, namely information control ( $\alpha=.73)$ and alliance importance $(\alpha=.81)$, and two instrument variables for communication quality, namely commitment $(\alpha=.85)$ and resource similarity (composite measure). The instruments were significantly correlated with the potentially endogenous 
variables, but not with opportunistic behavior. First-stage regressions showed significant effects of the instruments on the respective endogenous variable. Further tests indicated that the instruments were exogenous (Kleibergen-Paap rk LM statistic $=9.55, p<.01$ ), relevant (Hansen $\mathrm{J}$ statistic $<1.17, n s)$ and non-redundant $\left(X^{2}>5.04, p<.10\right)$. Angrist-Pischke statistics of 4.80 for formalization and 10.71 for communication quality confirmed instrument strength for the latter and thus power of endogeneity tests (Doko Tchatoka and Dufour, 2013). Finally, the Durbin-Wu-Hausman test indicated that formalization and communication quality did not create an endogeneity problem in the models for strategic manipulation $(F=1.99, p>$ $.10)$ and knowledge appropriation $(F=1.97, p>.10)$, which was confirmed by additional $C$ Tests (Baum et al., 2007). We therefore decided to rely on OLS regression rather than on IV regression.

\section{RESULTS}

Table 1 provides the descriptive statistics and correlation matrix. Table 2 reports the regression results. Following procedures suggested by Aiken and West (1991), coefficients were standardized for better interpretation. Further analyses point to no serious threat of multicollinearity. ${ }^{9}$

Please insert Tables 1 and 2 about here

Hypothesis 1 suggested that formalization increases opportunistic behavior perceived by the technology venture. Formalization was positively related to knowledge appropriation (Model 5: $\beta=.66, p<.05$ ). While the relationship with strategic manipulation was also positive, it was weakly significant in Model $2(\beta=.22, p<.10)$, but significant for the conditional effect in Model $3(\beta=.28, p<.05)$. Overall, the findings support Hypothesis 1. Consistent with Hypothesis 2, communication quality was negatively related with strategic 
manipulation (Model 2: $\beta=-.43, p<.01$ ) and knowledge appropriation (Model 5: $\beta=-.75, p$ $<.05)$. Hypothesis 3 predicted interactive effects on opportunistic behavior between formalization and communication quality. Significant interactions were found for strategic manipulation (Model 3: $\beta=-.38, p<.001$ ), but not for knowledge appropriation (Model 6: $\beta$ $=.15$, n.s.). To advance further interpretations, we plotted the interaction effect for low/high levels of the moderator, defined as minus/plus one standard deviation from the mean (Figure 1). We also performed a simple slope analysis to test whether the slopes were different from zero (Aiken and West, 1991). The results confirmed the visual impression obtained from Figure 1. In other words, high communication quality mitigates the positive effect of formalization on strategic manipulation. Overall, Hypothesis 3 received partial support.

Please insert Figure 1 about here

According to a final set of hypotheses, the relationships suggested in Hypotheses 1 to 3 depend on the type of opportunistic behavior. We used the seemingly unrelated estimation (SUEST) algorithm in Stata 11 to examine whether coefficients significantly differed across models. The results support Hypothesis 4a: formalization had a stronger positive relationship with knowledge appropriation than with strategic manipulation $\left(X^{2}=3.84, p<.05\right)$. However, both forms of opportunistic behavior did not differ regarding the effect of communication quality $\left(X^{2}=3.84\right.$, n.s.). Hypothesis $4 \mathrm{~b}$ thus received no support. Hypothesis $4 \mathrm{c}$ suggested that the mitigating effect of communication quality on formalization is stronger for strategic manipulation than for knowledge appropriation. The interaction effect was significant for the prior (Model 3: $\beta=-.38, p<.001$ ) but not the latter (Model 6: $\beta=.15$, n.s.). Similarly, SUEST provided (weakly) significant findings that the interaction was more negative for strategic manipulation than for knowledge appropriation $\left(X^{2}=2.76, p<.10\right)$. Overall, we found weak support for Hypothesis 4c. 


\section{DISCUSSION AND IMPLICATIONS}

Among the many risks of alliances, opportunistic behavior is widely considered one of the most salient (Wathne and Heide, 2000; Williamson, 1985). Deploying effective safeguards is therefore critical to realizing value within alliances. Transaction cost economics (Williamson, 1985) and agency theory (Jensen and Meckling, 1976) suggest formalization as one preventive mechanism, but empirical research has yielded mixed findings on its efficacy in alliances (e.g., Deeds and Hill, 1999; Luo, 2007a). Thus, does formalization and, if so, when does formalization deter opportunistic behavior in $R \& D$ alliances? In our attempt to address these questions, this article started with distinguishing two forms of active opportunism, namely strategic manipulation and knowledge appropriation. It then drew on the literature on coordination, cooperation, and sensemaking to posit that formalization promotes opportunistic behavior in $R \& D$ alliances, as perceived by a focal technology venture (Hypothesis 1). Communication quality has, as was further suggested, beneficial effects in that it directly mitigates perceived opportunistic behavior (Hypothesis 2) and reduces the dysfunctional effects of formalization (Hypothesis 3). The above effects are proposed to differ between knowledge appropriation and strategic manipulation (Hypotheses 4a-c).

Our first key result is that extensive formalization seems to fuel the insidious problem of perceived opportunistic behavior in R\&D alliances between competitors. This supports our arguments that formalization can enable or motivate a partner to actually behave more opportunistically, and/or it can lead the focal firm to perceive more opportunistic behavior, be it present or not. While this study hypothesized a linear effect of formalization, Vlaar et al. (2007b) proposed a curvilinear effect, namely that moderate rather than very low or very high levels of formalization are beneficial. Although additional analyses of our data could not confirm a u-shaped relationship between formalization and the two types of opportunistic behavior, both perspectives are not incommensurate. ${ }^{10}$ We argued above that some 
formalization is often inevitable in $R \& D$ alliances and widely regarded beneficial. Only if exaggerated, formalization may have dysfunctional effects. Our sample of R\&D alliances is, indeed, characterized by moderate to high levels of formalization $($ mean $=4.47$, median $=$ 5.00). Thus, our finding of a positive linear effect could be viewed as a crude approximation of the right side of the u-shape suggested by Vlaar et al. (2007b).

A second key result is that communication quality does not only directly reduce perceived opportunistic behavior, it also alleviates the positive impact of formalization on perceived strategic manipulation. ${ }^{11}$ While prior research has shown that communication generally facilitates alliance success by promoting the alignment of incentives (Agarwal et al., 2010) and mutual support (Mohr and Spekman, 1994) between the parties, our study suggests that communication quality helps prevent perceptions of opportunism and mitigates the adverse effects of formalization such as breeding distrust or increasing the likelihood of misunderstandings. Moreover, the presence or absence of communication quality is one possible explanation for the ambiguity of prior findings, if the underlying samples systematically varied in partner communication behavior.

A third key result is that the dysfunctional effect of formalization and the interactive effect of communication quality varied with the type of opportunism, which supports the call to further explore nuances of opportunism. However, we found no significant difference regarding communication quality. One possible explanation is the existence of a countervailing effect: strategic manipulation is overtly intentional, likely to be long-planned at the management level and severe. The offender accepts considerable risks of alliance termination and reputational damage and is thus likely to derive the main payoff from pursuing selfish, not collaborative goals. Since collaborative value creation is not the focus, strategic manipulation is relatively unaffected by communication quality. Finally and surprisingly, equity exchanges were positively related to knowledge appropriation. As one explanation, the partners might differ in their belief about when holding equity entitles to 
transferring and using company knowledge. Another explanation is that holding equity allowed participating in board meetings and therefore accelerated partner learning.

\section{Theoretical implications}

This study contributes to the literature in several ways. First, prior research with roots in transaction costs economics and agency theory tended to view formalization as a solution to opportunism in interfirm exchanges (e.g., Luo, 2007b; Williamson, 1985). More recently, this view has been challenged as studies on buyer-supplier relationships associated opportunism with certain forms of monitoring and control (Heide et al., 2007; Ju et al., 2011; Provan and Skinner, 1989). Our study extends this line of research by demonstrating a positive formalization-opportunism relationship in the context of $R \& D$ alliances. The finding raises further doubts on the universal effectiveness of formalization to suppress opportunistic behavior.

Second, our findings also add to the ongoing debate on formal and relational governance. Much research on relational governance has revolved around the notion of trust (e.g., Das and Teng, 1996, 1998, 2001; Lui and Ngo, 2004). While some scholars have viewed open communication as a facet of trust (e.g., Currall and Inkpen, 2002), our study proposes communication quality as a theoretically and empirically distinct concept that has an impact above and beyond trust. Moreover, some studies have found both formal and relational mechanisms to be complements (Faems et al., 2008; Li et al., 2010; Poppo and Zenger, 2002), others find them to be substitutes (Carson, Madhok, and Wu, 200; Gulati, 1995). Our results suggest an alternative perspective: relational governance (communication quality) compensates for the dysfunctional effects of formal governance (formalization). Thus, formalization mechanisms derived from agency theory and transaction cost economics are not sufficient in themselves but require continuous social interaction to remain effective. 
Third, although a more nuanced understanding of opportunism is warranted to find effective deterrents against opportunistic behavior, to date, only few scholars have responded to Wathe and Heide's (2000) call (Das and Kumar, 2011; Jap et al., 2013; Lumineau and Quélin, 2012). This study conceptualized two distinct forms of opportunism salient in the context of R\&D alliances, namely strategic manipulation and knowledge appropriation. More importantly, our findings confirm that differentiating forms of opportunism matters: the dysfunctional effect of formalization was stronger for knowledge appropriation, whereas the interactive effect of communication quality was stronger for strategic manipulation. Our results point to a new challenge of matching, theoretically and empirically, safeguards and types of opportunism. This includes finding and categorizing further types of opportunism beyond the existing categorization of active-passive opportunism (Wathne and Heide, 2000) or low-stakes-high-stakes opportunism (Jap et al., 2013), without introducing unnecessary complexity.

\section{Managerial implications}

Why and when partners behave opportunistically is a key question for alliance managers, especially when they are entrusted with the development of R\&D coopetitions. Our findings emphasize the need for judicious alliance governance because excessive efforts to control collaborative processes and partner behavior, thus tendencies to 'over-formalize', may spur opportunism. Since extensive contracts and work plans suppress, as we argue, intrinsic motivation and a climate of cooperation, competing partners should carefully examine the need to formalize before engaging in $R \& D$ alliances. Moreover, managers should communicate in an open and honest manner, in order to foster value creation in the alliance and reduce temptations to behave opportunistically. Although such communication may produce a positive atmosphere for interfirm decision-making and ultimately trust, communication and trust are distinct concepts. This implies that managers can cultivate open 
communication while maintaining some 'healthy distrust' and that communication quality can be a first step towards interfirm trust. Our study also indicates that open and honest communication attenuates the adverse effects of formalization. Strategic manipulation in $\mathrm{R} \& \mathrm{D}$ alliances is lower when formal and relational governance are used together. This insight is important because a certain level of formalization is often inevitable to enable knowledge sharing processes that are critical for R\&D alliance success.

\section{Limitations and future research}

The limitations of this study indicate promising potential approaches for future work. First, in using cross-sectional data, the study provides no insights into partnership dynamics. Future research could therefore adopt longitudinal designs to illuminate how opportunism emerges from the sequence of action and reaction by each partner. Second, the study focuses on ways of minimizing risks and costs, rather than on ways of creating value $R \& D$ alliances (Dyer and Singh, 1998). Gaining a comprehensive understanding of value creation in such partnerships may require to incorporate both aspects — another interesting avenue for subsequent research. Third, we sample alliances between (potential) competitors in Germany in which one partner was a technology venture. Thus, our results are conditional and for the most part can be generalized just to this context. Still, we have no a priori reason to believe they would not generalize to other settings, in particular to alliances of non-competing partners. Fourth, while our study has focused on two facets of active opportunism, many other facets may exist and constitute exciting avenues for further research. Sixth, we cannot rule out that some respondents tended to report on more successful alliances. However, given that most firms had only one alliance with competitors that met our sampling criteria, the risk of such a selection bias distorting our results appears to be low. Seventh, we have relied on a simple formative measure of knowledge appropriation. Future research could further refine this measure, for instance by creating and validating a second-order construct and testing the 
construct domain in other country contexts. Finally, we theorize on three possible

mechanisms, namely that formalization increases the likelihood of (1) actual partner opportunism, (2) detecting partner opportunism, and (3) misperceiving actual partner

opportunism. However, data limitations preclude, as it has in prior studies (e.g., Deeds and Hill, 1999; Luo, 2007a), empirically testing these explanations here. More research is therefore needed to further explore the detailed mechanisms underlying the adverse effects of formalization.

\section{REFERENCES}

Afuah, A. (2000). How Much do Your Co-Opetitors' Capabilities Matter in the Face of Technological Change? Strategic Management Journal 21:387-404.

Agarwal, R., Croson, R., and Mahoney, J.T. (2010). The Role of Incentives and Communication in Strategic Alliances: An Experimental Investigation. Strategic Management Journal 31(4):413-437.

Aiken, L.S. and West, S.G. (1991). Multiple Regressions: Testing and Interpreting Interactions. Newbury Park et al.: Sage.

Alvarez, S.A. and Barney, J.B. (2001). How Entrepreneurial Firms Can Benefit from Alliances with Large Partners. Academy of Management Executive 15(1):139-148.

Anderson, J.C. and Narus, J.A. (1990). A Model of Distributor Firm and Manufacturer Firm Working Partnerships. Journal of Marketing 54(1):42-58.

Ang, S.H. (2008). Competitive Intensity and Collaboration: Impact on Firm Growth Across Technological Environments. Strategic Management Journal 29(10):1057-1075.

Ariño, A., Ragozzino, R., and Reuer, J.J. (2008). Alliance Dynamics for Entrepreneurial Firms. Journal of Management Studies 45(1):147-168.

Barney, J.B. and Hesterly, W. (2006). Organizational Economics: Understanding the Relationship between Organizations and Economic Analysis. In: The SAGE Handbook of Organization Studies, S. Clegg, C. Hardy, and W. Nord (eds.), 115-147.

Baum, C.F., Schaffer, M.E., and Stillman, S. (2007). Enhanced Routines for Instrumental Variables/Generalized Methods of Moments Estimating and Testing. The Stata Journal 7(4):465-506.

Baum, J.A.C., Calabrese, T., and Silverman, B.S. (2000). Don't Go It Alone: Alliance Network Composition and Startups' Performance in Canadian Biotechnology. Strategic Management Journal 21:267-294.

Bengtsson, M. and Kock, S. (2000). "Coopetition” in Business Networks - To Cooperate and Compete Simultaneously. Industrial Marketing Management 29:411-426.

Blatt, R. (2009). Tough Love: How Communal Schemas and Contracting Practices Build Relational Capital in Entrepreneurial Teams. Academy of Management Review 34(3):533-551.

Business Week. (2003). Death of a Dream at Sendo. http://www.businessweek.com/stories/2003-02-09/death-ofa-dream-at-sendo. 2014-02-28. 
Carson, S.J., Madhok, A., and Wu, T. (2006). Uncertainty, Opportunism, and Governance: The Effects of Volatility and Ambiguity on Formal and Relational Contracting. Academy of Management Journal 49(5):10581077.

Coase, R.H. (1988). The Nature of the Firm: Origin, Meaning, Influence. Journal of Law, Economics \& Organization 4(1):3-47.

Cohen, W.M. and Levinthal, D.A. (1990). Absorptive Capacity: A New Perspective on Learning and Innovation. Administrative Science Quarterly 35(1):128-152.

Crosno, J.L. and Dahlstrom, R. (2008). A Meta-Analytic Review of Opportunism in Exchange Relationships. Journal of the Academy of Marketing Science 36(2):191-201.

Currall, S.C. and Inkpen, A.C. (2002). A Multilevel Approach to Trust in Joint Ventures. Journal of International Business Studies 33(3):479-495.

Czepiel, J.A. (1974). Word-of-Mouth Processes in the Diffusion of a Major Technological Innovation. Journal of Marketing Research 11(2):172-180.

Das, T.K. and Teng, B.-S. (1996). Risk Types and the Inter-Firm Alliances Structures. Journal of Management Studies 33(6):827-843.

Das, T.K. and Teng, B.-S. (1998). Between Trust and Control: Developing Confidence in Partner Cooperation in Alliances. Academy of Management Review 23(3):491-512.

Das, T.K. and Teng, B.-S. (2001). Trust, Control, and Risk in Strategic Alliances: An Integrated Framework. Organization Studies 22(2):251-273.

Das, T.K. and Rahman, N. (2002). Opportunism Dynamics in Strategic Alliances. In: Cooperative Strategies and Alliances, F.J. Contractor and P. Lorange (eds.). Oxford: Elsevier Science, 89-118.

Das, T.K. (2004). Time-Span and Risk of Partner Opportunism in Strategic Alliances. Journal of Managerial Psychology 19(8):744-759.

Das, T.K. (2005). Deceitful Behaviors of Alliance Partners: Potential and Prevention. Management Decision 43(5):706-719.

Das, T.K. and Kumar, R. (2011). Regulatory Focus and Opportunism in the Alliance Development Process. Journal of Management 37(3):682-708.

Deeds, D.L. and Hill, C.W.L. (1999). An Examination of Opportunistic Action Within Research Alliances: Evidence From the Biotechnology. Journal of Business Venturing 14(2):141-163.

Dickson, P.H., Weaver, K.M., and Hoy, F. (2006). Opportunism in the R\&D Alliances of SMES: The Roles of the Institutional Environment and SME Size. Journal of Business Venturing 21(4):487-513.

Doko Tchatoka, F. and Dufour, J.-M. (2013). On the Finite-Sample Theory of Exogeneity Tests with Possibly Non-Gaussian Errors and Weak Identification. McGill University.

Doz, Y.L. (1987). Technology Partnerships between Larger and Smaller Firms: Some Critical Issues. International Studies of Management \& Organization 17(4):31-57.

Doz, Y.L. (1996). The Evolution of Cooperation in Strategic Alliances: Initial Conditions or Learning Processes? Strategic Management Journal 17:55-83.

Dussauge, P., Garrette, B., and Mitchell, W. (2000). Learning from Competing Partners: Outcomes and Durations of Scale and Link Alliances in Europe, North America and Asia. Strategic Management Journal 21(2):99-126.

Dyer, J.H. and Singh, H. (1998). The Relational View: Cooperative Strategy and Sources of Interorganizational Competitive Advantage. Academy of Management Review 23(4):660-679. 
Echambadi, R. and Hess, J.D. (2007). Mean-Centering Does Not Alleviate Collinearity Problems in Moderated Multiple Regression Models. Marketing Science 26(3):438-445.

Eisenhardt, K.M. (1989). Agency Theory: An Assessment and Review. Academy of Management Review 14(1):57-74.

Emden, Z., Calantone, R.J., and Droge, C. (2006). Collaborating for New Product Development: Selecting the Partner with Maximum Potential to Create Value. Journal of Product Innovation Management 23(4):330-341.

Faems, D., Janssens, M., Madhok, A., and Van Looy, B. (2008). Toward an Integrative Perspective on Alliance Governance: Connecting Contractual Design, Trust Dynamics and Contract Application. Academy of Management Journal 51(6):1053-1078.

Falk, A. and Kosfeld, M. (2006). The Hidden Costs of Control. American Economic Review 96(5):1611-1630.

Ghoshal, S. and Moran, P. (1996). Bad for Practice: A Critique of the Transaction Cost Theory. Academy of Management Review 21(1):13-47.

Gnyawali, D.R., He, J., and Madhavan, R. (2006). Impact of Co-Opetition on Firm Competitive Behavior: An Empirical Examination. Journal of Management 32(4):507-530.

Granovetter, M. (1985). Economic Action and Social Structure: The Problem of Embeddedness. American Journal of Sociology 91(3):481-510.

Gulati, R. (1995). Does Familiarity Breed Trust? The Implications of Repeated Ties for Contractual Choice in Alliances. Academy of Management Journal 38(1):85-112.

Gulati, R. (1998). Alliances and Networks. Strategic Management Journal 19(4):293-317.

Gulati, R., Lawrence, P.R., and Puranam, P. (2005). Adaptation in Vertical Relationships: Beyond Incentive Conflict. Strategic Management Journal 26(5):415-440.

Gulati, R., Wohlgezogen, F., and Zhelyazkov, P. (2012). The Two Facets of Collaboration: Cooperation and Coordination in Strategic Alliances. The Academy of Management Annals 6(1):531-583.

Gundlach, G.T., Achrol, R.S., and Mentzer, J.T. (1995). The Structure of Commitment in Exchange. Journal of Marketing 59(1):78-92.

Hamel, G. (1991). Competition for Competence and Inter-Partner Learning Within International Strategic Alliances. Strategic Management Journal 12(Special Issue):83-103.

Hawkins, T.G., Wittmann, C.M., and Beyerlein, M.M. (2008). Antecedents and Consequences of Opportunism in Buyer-Supplier Relations: Research Synthesis and New Frontiers. Industrial Marketing Management 37(8):895-909.

Heide, J.B. and John, G. (1988). The Role of Dependence Balancing in Safeguarding Transaction-Specific Assets in Conventional Channels. Journal of Marketing 52(1):20-35.

Heide, J.B., Wathne, K.H., and Rokkan, A.I. (2007). Interfirm Monitoring, Social Contracts, and Relationship Outcomes. Journal of Marketing Research 44(3):425-433.

Jap, S.D. and Ganesan, S. (2000). Control Mechanisms and the Relationship Life Cycle: Implications for Safeguarding Specific Investments and Developing Commitment. Journal of Marketing Research 37(2):227245.

Jap, S.D. and Anderson, E. (2003). Safeguarding Interorganizational Performance and Continuity under Ex Post Opportunism. Management Science 49(12):1684-1701.

Jap, S.D., Robertson, D.C., Rindfleisch, A., and Hamilton, R. (2013). Low-Stakes Opportunism. Journal of Marketing Research 50(2):216-227. 
Jarvis, C.B., Mackenzie, S.B., and Podsakoff, P.M. (2003). A Critical Review of Construct Indicators and Measurement Model Misspecification in Marketing and Consumer Research. Journal of Consumer Research 30(2):199-218.

Jassawalla, A.R. and Sashittal, H.C. (1998). An Examination of Collaboration in High-Technology New Product Development Processes. Journal of Product Innovation Management 15(3):237-254.

Jensen, M.C. and Meckling, W.H. (1976). Theory of the Firm: Managerial Behavior, Agency Costs and Ownership Structure. Journal of Financial Economics 3(4):305-360.

Ju, M., Murray, J.Y., Kotabe, M., and Gao, G.Y. (2011). Reducing Distributor Opportunism in the Export Market: Effects of Monitoring Mechanisms, Norm-Based Information Exchange, and Market Orientation. Journal of World Business 46(4):487-496.

Judge, W.Q. and Dooley, R. (2006). Strategic Alliance Outcomes: a Transaction-Cost Economics Perspective. British Journal of Management 17(1):23-37.

Katila, R., Rosenberger, J.D., and Eisenhardt, K.M. (2008). Swimming with Sharks: Technology Ventures, Defense Mechanisms and Corporate Relationships. Administrative Science Quarterly 53(2):295-332.

Kogut, B. (2000). The Network as Knowledge: Generative Rules and the Emergence of Structure. Strategic Management Journal 21:405-425.

Larson, A. (1992). Network Dyads in Entrepreneurial Settings: A Study of the Governance of Exchange Relationships. Administrative Science Quarterly 37(1):76-104.

Lhuillery, S. and Pfister, E. (2009). R\&D Cooperation and Failures in Innovation Projects: Empirical Evidence from French CIS Data. Research Policy 38(1):45-57.

Li, D., Eden, L., Hitt, M.A., and Ireland, R.D. (2008). Friends, Acquaintances, or Strangers? Partner Selection in R\&D Alliances. Academy of Management Journal 51(2):315-334.

Li, J.J., Poppo, L., and Zhou, K.Z. (2010). Relational Mechanisms, Formal Contracts, and Local Knowledge Acquisition by International Subsidiaries. Strategic Management Journal 31(4):349-370.

Liebeskind, J.P. (1996). Knowledge, Strategy, and the Theory of the Firm. Strategic Management Journal 17:93107.

Lui, S.S. and Ngo, H.-Y. (2004). The Role of Trust and Contractual Safeguards on Cooperation in Non-equity Alliances. Journal of Management 30(4):471-485.

Lui, S.S., Wong, Y.-y., and Liu, W. (2009). Asset Specificity Roles in Interfirm Cooperation: Reducing Opportunistic Behavior or Increasing Cooperative Behavior? Journal of Business Research 62(11):1214-1219.

Lumineau, F. and Quélin, B.V. (2012). An Empirical Investigation of Interorganizational Opportunism and Contracting Mechanisms. Strategic Organization 10(1):55-84.

Luo, Y. (2002). Contract, Cooperation, and Performance in International Joint Ventures. Strategic Management Journal 23(10):903-919.

Luo, Y. (2007a). An Integrated Anti-Opportunism System in International Exchange. Journal of International Business Studies 38(6):855-878.

Luo, Y. (2007b). Are Joint Venture Partners More Opportunistic in a More Volatile Environment? Strategic Management Journal 28(1):39-60.

Lusch, R.F. and Brown, J.R. (1996). Interdependency, Contracting, and Relational Behavior in Marketing Channels. Journal of Marketing 60(4):19-38. 
MacKenzie, S.B., Podsakoff, P.M., and Jarvis, C.B. (2005). The Problem of Measurement Model Misspecification in Behavioral and Organizational Research and Some Recommended Solutions. Journal of Applied Psychology 90(4):710-730.

Macneil, I.R. (1980). The New Social Contract : An Inquiry into Modern Contractual Relations. New Haven u.a.: Yale University Press.

Malhotra, D. and Lumineau, F. (2011). Trust and Collaboration in the Aftermath of Conflict: The Effects of Contract Structure. Academy of Management Journal 54(5):981-998.

Mellewigt, T., Madhok, A., and Weibel, A. (2007). Trust and Formal Contracts in Interorganizational Relationships - Substitutes and Complements. Managerial \& Decision Economics 28(8):833-847.

Mohr, J. and Spekman, R. (1994). Characteristics of Partnership Success: Partnership Attributes, Communication Behavior, and Conflict Resolution Techniques. Strategic Management Journal 15(2):135-152.

Nooteboom, B. (1996). Trust, Opportunism and Governance: A Process and Control Model. Organization Studies 17(6):985-1010.

Norman, P.M. (2004). Knowledge Acquisition, Knowledge Loss, and Satisfaction in High Technology Alliances. Journal of Business Research 57(6):610-619.

Oxley, J.E. (1997). Appropriability Hazards and Governance in Strategic Alliances: A Transaction Cost Approach. Journal of Law, Economics, \& Organization 13(2):387-409.

Park, S.H. and Russo, M.V. (1996). When Competition Eclipses Cooperation: An Event History Analysis of Joint Venture Failure. Management Science 42(6):875-890.

Park, S.H. and Kim, D. (1997). Market Valuation of Joint Ventures: Joint Venture Characteristics and Wealth Gains. Journal of Business Venturing 12(2):83-108.

Park, S.H. and Ungson, G.R. (2001). Interfirm Rivalry and Managerial Complexity: A Conceptual Framework of Alliance Failure. Organization Science 12(1):37-53.

Parkhe, A. (1993). Strategic Alliance Structuring: A Game Theoretic and Transaction Cost Examination of Interfirm Cooperation. Academy of Management Journal 36(8):794-829.

Peteraf, M.A. and Bergen, M.A. (2003). Scanning Dynamix Competitive Landscapes: A Market-Based and Resource-Based Framework. Strategic Management Journal 24(10):1027-1041.

Poppo, L. and Zenger, T. (2002). Do Formal Contracts and Relational Governance Function as Substitutes or Complements? Strategic Management Journal 23(8):707-725.

Provan, K.G. and Skinner, S.J. (1989). Interorganizational Dependence and Control as Predictors of Opportunism in Dealer-Supplier Relations. Academy of Management Journal 32(1):202-212.

Reuer, J.J. and Ariño, A. (2002). Contractual Renegotiations in Strategic Alliances. Journal of Management 28(1):47-68.

Rossiter, J.R. (2002). The C-OAR-SE Procedure for Scale Development in Marketing. International Journal of Research in Marketing 19(4):305-335.

Ryall, M.D. and Sampson, R.C. (2009). Formal Contracts in the Presence of Relational Enforcement Mechanisms: Evidence from Technology Development Projects. Management Science 55(6):906-925.

Sampson, R.C. (2005). Experience Effects and Collaborative Returns in R\&D Alliances. Strategic Management Journal 26(11):1009-1031.

Sampson, R.C. (2007). R\&D Alliances and Firm Performance: The Impact of Technological Diversity and Alliance Organization on Innovation. Academy of Management Journal 50(2):364-386. 
Sarkar, M.B., Echambadi, R., Cavusgil, S.T., and Aulakh, P.S. (2001). The Influence of Complementarity, Compatibility, and Relationship Capital on Alliance Performance. Journal of the Academy of Marketing Science 29(4):358-373.

Schweitzer, M.E., Ordóñez, L., and Douma, B. (2004). Goal Setting as a Motivator of Unethical Behavior. Academy of Management Journal 47(3):422-432.

Sherwood, A.L. and Covin, J.G. (2008). Knowledge Acquisition in University-Industry Alliances: An Empirical Investigation from a Learning Theory Perspective. Journal of Product Innovation Management 25(2):162-179.

Sin, L.Y.M., Tse, A.C.B., Yau, O.H.M., Chow, R.P.M., Lee, J.S.Y., and Lau, L.B.Y. (2005). Relationship Marketing Orientation: Scale Development and Cross-Cultural Validation. Journal of Business Research 58(2):185-194.

Singh, K. and Mitchell, W. (1996). Precarious Collaboration: Business Survival after Partners Shut Down or Form New Partnerships. Strategic Management Journal 17(Special Issue):99-115.

Sivadas, E. and Dwyer, F.R. (2000). An Examination of Organizational Factors Influencing New Product Success in Internal and Alliance-Based Processes. Journal of Marketing 64(1):31-49.

Stephen, A.T. and Coote, L.V. (2007). Interfirm Behavior and Goal Alignment in Relational Exchanges. Journal of Business Research 60(4):285-295.

van de Vrande, V., Vanhaverbeke, W., and Duysters, G. (2011). Technology In-Sourcing and the Creation of Pioneering Technologies. Journal of Product Innovation Management 28(6):974-987.

Vanhaverbeke, W., Gilsing, V., and Duysters, G. (2012). Competence and Governance in Strategic Collaboration: The Differential Effect of Network Structure on the Creation of Core and Noncore Technology. Journal of Product Innovation Management 29(5):784-802.

Vlaar, P.W.L., van den Bosch, F.A.J., and Volberda, H.W. (2006). Coping with Problems of Understanding in Interorganizational Relationships: Using Formalization as a Means to Make Sense. Organization Studies 27(11):1617-1638.

Vlaar, P.W.L., van den Bosch, F.A.J., and Volberda, H.W. (2007a). Towards a Dialectic Perspective on Formalization in Interorganizational Relationships: How Alliance Managers Capitalize on the Duality Inherent in Contracts, Rules and Procedures. Organization Studies 28(4):437-466.

Vlaar, P.W.L., van den Bosch, F.A.J., and Volberda, H.W. (2007b). On the Evolution of Trust, Distrust, and Formal Coordination and Control in Interorganizational Relationships: Toward an Integrative Framework. Group \& Organization Management 32(4):407-429.

Wall Street Journal. (2002). Net2Phone Sues Cisco Systems Over Contract, Competition Issues. 20 March 2002.

Walter, S.G., Müller, D., and Walter, A. (2010). Dysfunktionen in F\&E-Koopetitionen: Präventivmaßnahmen und Kooperationserfolg. Zeitschrift für betriebswirtschaftliche Forschung 62(3):134-159.

Wathne, K.H. and Heide, J.B. (2000). Opportunism in Interfirm Relationships: Forms, Outcomes, and Solutions. Journal of Marketing 64(4):36-51.

Williamson, O.E. (1975). Markets and Hierarchies. New York: Free Press.

Williamson, O.E. (1985). The Economic Institutions of Capitalism. New York: The Free Press.

Wooldridge, J.M. (2003). Introductory Econometrics : A Modern Approach, 2nd ed. Australia ; Cincinnati, Ohio: South-Western College Pub.

Zeng, M. and Chen, X.-P. (2003). Achieving Cooperation in Multiparty Alliances: A Social Dilemma Approach to Partnership Management. Academy of Management Review 28(4):587-605. 
Figure 1

Moderating effect of communication quality on the relationship between formalization and strategic manipulation

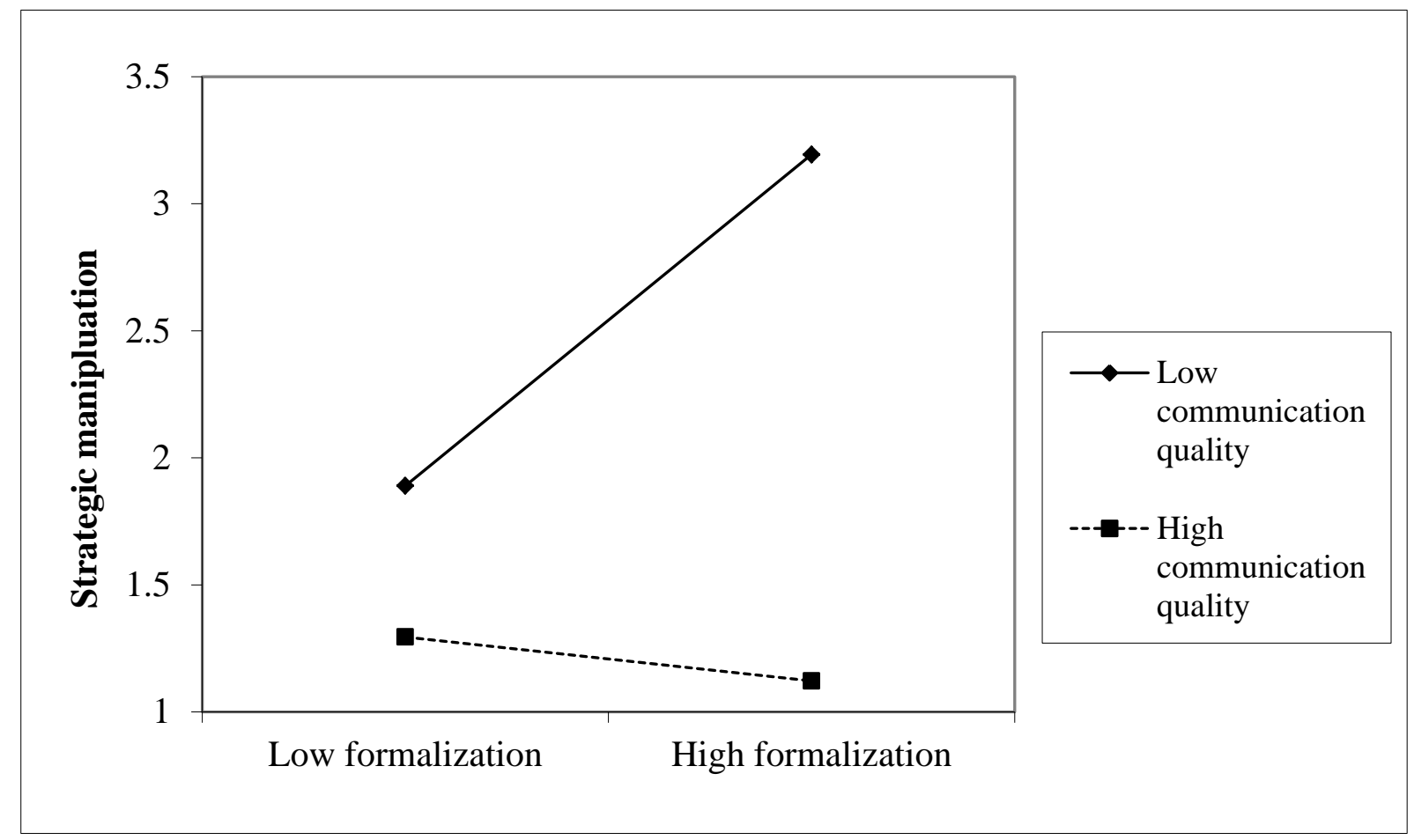


Table 1

Descriptive statistics and correlations ${ }^{\mathrm{a}}$

\begin{tabular}{|c|c|c|c|c|c|c|c|c|c|c|c|c|}
\hline Variable & Mean & SD & 1 & 2 & 3 & 4 & 5 & 6 & 7 & 8 & 9 & 10 \\
\hline 1. Strategic manipulation & 1.76 & 1.15 & - & & & & & & & & & \\
\hline 2. Knowledge appropriation & 5.96 & 2.71 & $0.41^{* * *}$ & - & & & & & & & & \\
\hline 3. Formalization & 4.47 & 1.93 & 0.15 & $0.20^{\mathrm{t}}$ & - & & & & & & & \\
\hline 4. Communication quality & 4.95 & 1.23 & $-0.51^{* * *}$ & $-0.27^{*}$ & 0.05 & - & & & & & & \\
\hline 5. Equity exchanges ${ }^{\mathrm{b}}$ & 0.11 & 0.31 & 0.04 & 0.13 & 0.04 & 0.11 & - & & & & & \\
\hline 6. Cooperation experience & 10.96 & 11.60 & 0.06 & $0.22^{*}$ & 0.00 & -0.10 & 0.06 & - & & & & \\
\hline 7. Cooperation duration & 4.74 & 1.44 & 0.05 & -0.03 & $0.27^{*}$ & -0.05 & -0.11 & -0.08 & - & & & \\
\hline 8. Risk of opportunism & 6.71 & 5.99 & -0.10 & -0.15 & $0.22^{t}$ & 0.13 & -0.10 & -0.02 & 0.10 & - & & \\
\hline 9. Learning intent & 36.38 & 29.86 & -0.14 & 0.01 & -0.10 & $0.25^{*}$ & 0.11 & $-0.20^{\mathrm{t}}$ & -0.10 & -0.18 & - & \\
\hline 10. Trust & 5.31 & 1.48 & $-0.29^{* *}$ & -0.06 & 0.09 & $0.40^{* * *}$ & 0.00 & -0.06 & 0.10 & 0.18 & 0.06 & - \\
\hline 11. Goal congruence & 6.24 & 0.78 & $-0.41^{* * *}$ & $-0.24^{*}$ & 0.05 & $0.44^{* * * *}$ & 0.07 & $-0.22^{*}$ & 0.03 & 0.08 & $0.20^{\mathrm{t}}$ & $0.20^{\mathrm{t}}$ \\
\hline
\end{tabular}




\section{Table 2}

Regression results for strategic manipulation and knowledge appropriation ${ }^{\text {a }}$

\begin{tabular}{|c|c|c|c|c|c|c|c|c|c|c|}
\hline & \multicolumn{6}{|c|}{ Strategic manipulation } & \multicolumn{4}{|c|}{ Knowledge appropriation } \\
\hline & \multicolumn{2}{|c|}{ Model 1} & \multicolumn{2}{|c|}{ Model 2} & \multicolumn{2}{|c|}{ Model 3} & Model 4 & Model 5 & \multicolumn{2}{|c|}{ Model 6} \\
\hline & $\beta$ & $\overline{\text { se }}$ & $\beta$ & $\overline{\text { se }}$ & $\beta$ & $\overline{\text { se }}$ & $\beta$ se & $\boldsymbol{\beta}$ & $\beta$ & $\overline{\text { se }}$ \\
\hline \multicolumn{11}{|l|}{ Control variables } \\
\hline Equity exchanges $^{\mathrm{b}}$ & .10 & .12 & .09 & .11 & .10 & .10 & $.64^{*} .30$ & $.59^{*} .29$ & $9.59^{*}$. & .29 \\
\hline Cooperation experience & -.05 & .12 & -.06 & .12 & -.02 & .11 & -.26 .30 & $-.31 \quad .30$ & $0-.33$. & .30 \\
\hline Cooperation duration & -.09 & .13 & -.01 & .12 & .04 & .11 & .10 .31 & $.27 \quad .30$ & 0.26. & .30 \\
\hline Risk of opportunism & -.06 & .12 & -.05 & .11 & -.03 & .11 & .49 .30 & $.49^{\mathrm{t}} .29$ & $9.48^{\mathrm{t}}$. & .29 \\
\hline Learning intent & .09 & .12 & .00 & .12 & -.01 & .11 & .10 .30 & $\begin{array}{ll}-.12 \quad .29\end{array}$ & $9-.12$. & .30 \\
\hline Trust & $-.25^{*}$ & .12 & -.12 & .12 & -.04 & .11 & .00 .30 & $.21 \quad .31$ & 1.18. & .31 \\
\hline Goal congruence & $-.42^{* * *}$ & .12 & $-.28^{*}$ & .12 & $-.26^{*}$ & .12 & $-.58^{t} .31$ & $-.34 \quad .31$ & $1-.35$. & .32 \\
\hline \multicolumn{11}{|l|}{ Main effects } \\
\hline Formalization & & & $.22^{\mathrm{t}}$ & .12 & $.28^{*}$ & .11 & & $.66^{*} .30$ & $0.63^{*}$. & \\
\hline Communication quality & & & $-.43^{* * *}$ & .13 & $-.52^{* * * *}$ & .13 & & $-.75^{*} .34$ & $4-.72^{*}$. & .35 \\
\hline
\end{tabular}

\section{Interaction effects}

Formalization $\mathrm{x}$ communication quality

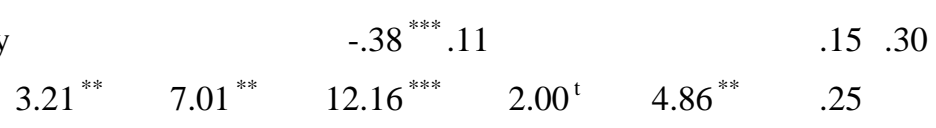

F-value

$\begin{array}{lllllll}\mathrm{R}^{2} & .23 & .36 & .45 & .16 & .26 & .26\end{array}$

adj. $\mathrm{R}^{2}$

$\begin{array}{lll}.16 & .28 & .38\end{array} \quad .08$

$.17-.16$

${ }^{\mathrm{a}} \mathrm{n}=82$; standardized coefficients. ${ }^{\mathrm{b}}$ Coding: $1=$ equity exchange, $0=$ otherwise.

${ }^{* * *} \mathrm{p}<.001$

${ }^{* *} \mathrm{p}<.01$

$p<.05$

${ }^{\mathrm{t}} \mathrm{p}<.10$ (two-tailed test). 
Strategic manipulation $(\alpha=.86, \mathrm{CR}=.86, \mathrm{AVE}=.69 ; \text { Informant } 2)^{\mathrm{a}}$

(1) The partner has manipulated the strategic direction of our firm during the cooperation.

(2) During the cooperation, the partner has hindered the further development of our firm.

(3) The partner has restrained our firm from reaching strategic goals through the

Knowledge appropriation (formative measure; Informant 2$)^{\mathrm{b}}$

(1) We have lost critical marketing and sales know-how to the partner.

(2) We have lost critical technological know-how to the partner.

(3) We have lost critical production know-how to the partner.

(4) We have lost critical management know-how to the partner.

Formalization $(\alpha=.95, \mathrm{CR}=.95, \mathrm{AVE}=.82 ;$ Informant 1$)$

(1) The processes of the cooperation were explicitly written down.

(2) The roles of the partners in the cooperation were explicitly written down.

(3) The responsibilities of the partners in the cooperation were explicitly written down.

(4) The contributions of the partners to the cooperation were explicitly written down.

Communication quality $(\alpha=.88, \mathrm{CR}=.89, \mathrm{AVE}=.61$; Informant 2$)$

(1) The partners can openly express their discontent towards each other.

(2) The partners can communicate honestly.

(3) The partners proactively provide timely and important information.

(4) The partners share proprietary information.

(5) The partners inform each other of changing project needs.

Learning intent $(\alpha=.76, \mathrm{CR}=.76, \mathrm{AVE}=.52$; Informant 1$)$

(1) We have defined for our firm in advance which competences we want to develop in the partnership.

(2) We have a clearly defined strategy to acquire knowledge in this partnership.

(3) We systematically process the knowledge acquired in this partnership for a future use in our firm.

Risk of opportunism (formative measure; Informant 1) ${ }^{\mathrm{a}}$

(1) It would have been very worthwhile for the partner to squeeze us out of the cooperationrelated markets.

(2) The partner had the potential to squeeze us out of the cooperation-related market.

Trust $(\alpha=.88, \mathrm{CR}=.88, \mathrm{AVE}=.72 ;$ Informant 1$)$

(1) We cannot always entirely trust the partner. (r)

(2) We are convinced that the partner will keep its promises.

(3) We rely on the partner competently and professionally performing its tasks.

Goal congruence $(\alpha=.62, \mathrm{CR}=.88, \mathrm{AVE}=.72 ;$ Informant 1$)$

(1) The goals were supported by the management of both partners.

(2) The goals suited the strategic direction of both partners.

(3) The goals of the partners were highly compatible.

$\alpha=$ Cronbach's Alpha; $\mathrm{CR}=$ Composite reliability; AVE = Average variance extracted. ${ }^{\text {a }}$ Informant $1:$ top manager or founder who negotiated the alliances; Informant 2: alliance or project manager who handled the partnership. ${ }^{\mathrm{b}}$ Conventional validity measures are irrelevant for formative scales. Model fit: $\chi^{2} / \mathrm{df}=1.73 ; \mathrm{CFI}=$ $.91 ; \mathrm{IFI}=.91$; Fornell-Larcker-Criterion confirmed . 
${ }^{1}$ In contrast to Vlaar et al. (2007a), enforcement is not included in our definition of formalization because startups and also other firms often lack the resources to enforce their rights. Moreover, our study focuses on formalization as preventive measure, whereas the need to enforce suggests that misconduct has already taken place.

${ }^{2}$ According to transaction cost economics, not all actors act opportunistically all the time, but it is difficult and costly to distinguish opportunistic actors from non-opportunistic ones and therefore prudent to behave as if all actors were opportunistic (Foss and Koch, 1996; Lado, Dant, and Tekleab, 2008). Our understanding of opportunism is more in line with sociological research suggesting that opportunism varies among economic actors and across situations (Gulati et al., 2012).

${ }^{3}$ Structural responses to this uncertainty include, for instance, internalizing partner activities (Williamson, 1975), more extensive contracting (Luo, 2002), or contractual renegotiations (Reuer and Ariño, 2002). A lack of resources and experience, however, may keep many technology ventures from using these options in ongoing partnerships (Ariño et al., 2008).

${ }^{4}$ Not surprisingly, alliances between competitors are less frequent (Ang, 2008) and fail more often (Lhuillery and Pfister, 2009; Park and Russo, 1996) than other alliances.

${ }^{5}$ In $43 \%$ of the cases, a second informant was unavailable as the informant had left the firm or was lacking the time to participate. Some firms were too small to have a separate alliance manager. However, analyses indicated that cases with and without a second informant did not significantly vary in terms of age, size, and technological field.

${ }^{6}$ One example for a process item is: "Sometimes my partner alters the facts in order to get what they need" (Deeds and Hill, 1999:163) and for an outcome item: "[M]y partner has sometimes promised to do things without actually doing them later" (Parkhe, 1993:828).

${ }^{7}$ The term 'lost' is colloquial and emphasizes that a knowledge flow (1) is unintended by the focal firm, (2) is not compensated by the profiting party, and (3) reduces the exclusivity and thus the value of this knowledge. However, strictly speaking, such flows do not decrease the firm's knowledge stock.

${ }^{8}$ Because formative indicators are not necessarily intercorrelated, reliability in terms of internal consistency and convergent validity are irrelevant in this case (Jarvis et al., 2003).

${ }^{9}$ The maximum variance inflation factors (VIF) were 1.56 for standardized data, 6.60 for raw data excluding the interaction term and 28.53 for raw data including the interaction term, whereas the maximum condition indices were 2.18, 34.33 and 65.57, respectively. However, Echambadi and Hess (2007) warn against false alarms from collinearity diagnostics, for instance because high VIFs are necessary but not sufficient to collinearity. Following their recommendation, we reran our estimations for five randomly selected subsets of the data. The coefficients were stable across the subsets and plausible, revealing no serious problems of multicollinearity.

${ }^{10}$ The results are available from the first author.

${ }^{11}$ We thank an anonymous reviewer for pointing us to another possibility: Since initial formal governance structures influence communication patterns between individuals from both partners (Faems et al., 2008; Vlaar et al., 2007a), communication quality could mediate the relationship between formalization and opportunistic behavior. However, our data does not support this notion, thereby providing further support for a moderating relationship. 